\title{
Serum Pepsinogen 1, Gastrin, ABO Blood Groups, Secretor Status of ABH Substances and Behavioral Factors in Patients with Duodenal Ulcer and Their Relatives
}

\author{
Koji SUMII, Naomi UemURA, Akira INBE, Manabu KIMURA, \\ Masaharu YoshIHARA, Ken HARUMA and Goro KAJIYAMA
}

\begin{abstract}
Serum pepsinogen 1, serum gastrin, ABO blood groups, secretor status of ABH blood group substances and behavioral factors were studied in 15 patients with duodenal ulcer and 61 their relatives affected and unaffected to duodenal ulcer. Duodenal ulcer patients had hyperpepsinogenemia 1 either with or without a positive family history of duodenal ulcer. Serum gastrin level was higher in duodenal ulcer patients and unaffected relatives with a positive family history of duodenal ulcer than those with a negative family history. Non secretor status was frequently observed in duodenal ulcer patients with a positive family history. There was no difference in behavioral factors between duodenal ulcer patients and unaffected relatives with a positive family history. It is concluded that genetically determined variables such as hyperpepsinogenemia 1 and non secretor status play an important role on the susceptibility to duodenal ulcer in subjects with a positive family history, and hypergastrinemia may be subclinical marker of familial aggregation of duodenal ulcer.
\end{abstract}

Key Words: $\quad$ Duodenal ulcer, Relatives, PGl, Gastrin, Secretor status

A significant proportion of duodenal ulcer patients have a positive family history of duodenal ulcer $^{1)}$. The results of family studies were consistent with the hypothesis that genetic factors play a role in the cause of duodenal ulcer ${ }^{2}$ ). The observations on blood group $\mathrm{O}$ and non secretor status have been constituting important evidence for the role of genetic factors in duodenal ulcer $^{3,4)}$. Recently, family studies have shown that hyperpepsinogenemia 1 was inherited as an autosomal dominant trait ${ }^{5,6}$. We, therefore, compared serum pepsinogen 1, gastrin, ABO blood groups, secretor status of $\mathrm{ABH}$ substances ${ }^{4,7)}$ and behavioral factors of duodenal ulcer patients (probands and their affected relatives) with those of unaffected relatives to elucidate the genetic role of duodenal ulcer developing in a familial basis.

\section{METHODS}

Seventy-six subjects consisted of 15 probands in whom duodenal ulcer was proven by endoscopy at Hiroshima University Hospital, and their 61 first-degree relatives. The probands and their first-degree relatives were asked about previous medical records, symptoms and behavioral factors. If proband and at least one of their first-degree relatives had a past endoscopic diagnosis of duodenal ulcer, a family history of duodenal ulcer was considered to be positive, and those families whose first-degree relatives had symptom suspicious of duodenal ulcer but had not been diagnosed by endoscopy were excluded from this study. Out of 61 relatives, 23 had past endoscopic diagnosis of duodenal ulcer and the remaining 38 had no

From The First Department of Internal Medicine, Hiroshima University School of Medicine. Hiroshima, Japan

Received for publication April 1988

Reprint request to: Koji Sumii, MD, The First Department of Internal Medicine,

Hiroshima University School of Medicine, 1-2-3 Kasumi, Minami-Ku, Hiroshima 734, Japan 
Table 1. Subjects

$\mathrm{n}$ male female age $(\mathrm{M} \pm \mathrm{SE})$

Positive family

history

$\begin{array}{lllll}\text { Affected } & 33 & 17 & 16 & 38.1 \pm 2.9 \\ \text { Unaffected } & 24 & 12 & 12 & 39.7 \pm 3.3\end{array}$

Negative family

history

\begin{tabular}{llrrrr} 
& Affected & 5 & 5 & 0 & $39.6 \pm 3.9$ \\
& Unaffected & 14 & 8 & 6 & $39.1 \pm 4.0$ \\
\hline Total & 76 & 42 & 34 &
\end{tabular}

affected: probands and the first-degree relatives with duodenal ulcer. unaffected: the first-degree relatives without duodenal ulcer.

clinical evidence of ulcer disease. Then subjects consisted of 38 affected relatives (duodenal ulcer patients) and 38 unaffected relatives (Table 1). No ulcer patient had been performed vagotomy or gastric resection before investigation. A positive family history was recorded in 10 families. The purpose of the study was explained, and each relative gave informed consent.

After an overnight fast, blood was collected and centrifuged. Serum was stored at $-20^{\circ} \mathrm{C}$ until determination of the fasting pepsinogen 1 and gastrin levels. Serum pepsinogen 1 was determined by radioimmunoassay kit (CIS). Serum gastrin was determined by radioimmunoassay as previously described $^{8)}$. ABO blood groups were determined by red blood cell and serum independently. Secretor status of $\mathrm{ABH}$ substances was determined using Lewis (a) antibody and Lewis (b) antibody purchased from Ortho Diagnostic System Inc. The Lewis $(a+b-)$ was considered to be non secretor and the Lewis $(a-b+)$ was secretor. In the case of Lewis $(a-b-)$, the saliva sample was tested to determine the secretor status. Subjects recorded behavioral factors as following: a) stress (yes or no), b) tobacco (more than 10 in a day or less), c) alcohol (drink every day or less), d) coffee (more than 2 cups in a day or less), e) sleep (disturbed or not), f) prefer spicy food or not.

The statistical significance of difference was determined by Student's t test and $\mathrm{X}^{2}$ test.

\section{RESULTS}

\section{Serum pepsinogen 1}

The serum pepsinogen 1 concentration to duodenal ulcer patients and unaffected relatives with a positive family history, and duodenal ulcer patients and unaffected relatives with a negative family history were $101.9 \pm 7.1 \mathrm{ng} / \mathrm{ml}$ (mean $\pm \mathrm{SE}$ ), $73.9 \pm 6.4 \mathrm{ng} / \mathrm{ml}), \quad 94.0 \pm 11.4 \mathrm{ng} / \mathrm{ml}$ and $54.0 \pm 4.8 \mathrm{ng} / \mathrm{ml}$. Then pepsinogen 1 level of duodenal ulcer patients were significantly higher than that of unaffected relatives either with or without a positive family history (Fig. 1 upper panel).

\section{Serum gastrin}

The serum gastrin levels of duodenal ulcer patients and unaffected relatives with a positive family history were $142.1 \pm 12.1 \mathrm{pg} / \mathrm{ml}$ and $121.8 \pm 15.5 \mathrm{pg} / \mathrm{ml}$. In duodenal ulcer patients and unaffected relatives with a negative family history the serum gastrin levels were $55.0 \pm 10.9 \mathrm{pg} / \mathrm{ml}$ and $69.1 \pm 6.3 \mathrm{pg} / \mathrm{ml}$.

The serum gastrin levels of duodenal ulcer patients and unaffected relatives with a positive family history were higher than those with a negative family history (Fig. 1 lower panel).

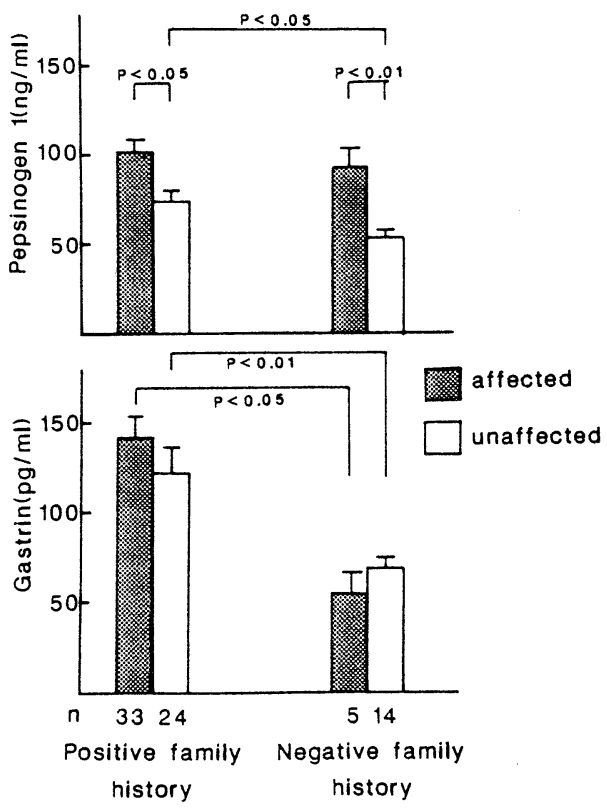

Fig. 1. Serum pepsinogen 1 and gastrin levels in subjects. 
3. ABO blood groups and secretor status

There was no difference in frequency of blood group $\mathrm{O}$ among duodenal ulcer patients and unaffected relatives with a positive family history, and those with a negative family history. Among four groups, the frequency of non secretor was highest in duodenal ulcer patients with a positive family history $(60.6 \%)$, in whom it was significantly higher than in unaffected relatives with a positive family history (Table 2 ).

\section{Behavioral factors}

In subjects with a positive family history, the frequency of each behavioral factor of duodenal ulcer patients did not differ from those of unaffected relatives. But in subjects with a negative family history the frequency of subjects having a stress and smoking more than 10 in a day was significantly higher in duodenal ulcer patients than in unaffected relatives (Table 3).

\section{DISCUSSION}

In the present study serum pepsinogen 1 was higher in duodenal ulcer patients than that of unaffected relatives in either with or without family history of duodenal ulcer, which implies that the subjects with elevated serum pepsinogen 1 are susceptible to duodenal ulcer. As hyperpepsinogenemia 1 was established to inherit as an autosomal dominant trait ${ }^{5,6}$, genetic factor play an important role on developing duodenal ulcer in a familial basis.

There was no such relation between hypergastrinemia and susceptibility to duodenal ulcer in familial basis. The serum gastrin level was significantly higher both in duodenal ulcer patients and unaffected relatives who have a positive family history of duodenal ulcer than those with a negative

Table 2. ABO blood groups and secretor status of subjects

\begin{tabular}{lrrrrrr}
\hline & \multicolumn{3}{c}{ Blood group } & \multicolumn{3}{c}{ Secretor status } \\
\cline { 2 - 7 } & 0 & Non 0 & $0(\%)$ & Se & Non Se Non Se(\%) \\
\hline Positive family & & & & & & \\
history & 11 & 22 & $33.3 \%$ & 13 & 20 & $60.6 \%$ \\
$\quad$ Affected & 8 & 16 & $33.3 \%$ & 20 & 4 & $16.7 \%$ \\
$\quad$ Unaffected & & & & & & \\
Negative family & & & & & & \\
history & 2 & 3 & $40.0 \%$ & 4 & 1 & $20.0 \%$ \\
$\quad$ Affected & 2 & 12 & $14.3 \%$ & 11 & 3 & $21.4 \%$ \\
$\quad$ Unaffected & & & & & & \\
\hline
\end{tabular}

Se: secretor NonSe: non secretor ${ }^{*}: \mathrm{p}<0.01$

Table 3. Behavioral factors

\begin{tabular}{|c|c|c|c|c|c|c|c|}
\hline & $\mathrm{n}$ & stress & tobacco & alcohol & coffee & sleep & spices \\
\hline \multicolumn{8}{|l|}{ Positive family } \\
\hline \multicolumn{8}{|l|}{ history } \\
\hline Affected & 33 & $15(45.5)$ & $12(36.4)$ & $9(27.3)$ & $8(24.2)$ & $5(15.2)$ & $14(42.4)$ \\
\hline Unaffected & 24 & $8(33.3)$ & $8(33.3)$ & $8(33.3)$ & $6(25.0)$ & $3(12.5)$ & $5(20.8)$ \\
\hline \multicolumn{8}{|l|}{ Negative family } \\
\hline \multicolumn{8}{|l|}{ history } \\
\hline Affected & 5 & $5(100) *$ & $5(100) *$ & $4(60.0)$ & $3(60.0)$ & $2(40.0)$ & $4(80.0)$ \\
\hline Unaffected & 14 & $4(28.6)$ & $4(28.6)$ & $4(28.6)$ & $4(28.6)$ & $1(7.1)$ & $3(21.4)$ \\
\hline
\end{tabular}

$*_{p}<0.05 \quad(\%)$ 
family history. Lam et $\mathrm{al}^{9)}$ also reported that postprandial serum gastrin level was increased in duodenal ulcer patients with a positive family history of ulcer, and supposed familial hypergastrinemia may be one marker for familial aggregation of duodenal ulcer. As mentioned above we confirmed that not only patients with duodenal ulcer but also unaffected relatives possessed hypergastrinemia, therefore hypergastrinemia is not subclinical marker of ulcer diathesis but the marker for familial aggregation of duodenal ulcer.

Duodenal ulcer patients were known to have excess incidence of blood group $\mathrm{O}$ and non secretor status $3,4,7)$. In the present study the frequency of non secretor was higher in the patients with duodenal ulcer than those of unaffected relatives who had a positive family history of duodenal ulcer, but the frequency of blood group $\mathrm{O}$ was same in both groups. Secretor status is determined genetically, and the gene for non secretor has an influence on the risk of development of duodenal ulcer in subjects of a positive family history.

Concerning behavioral factors, more patients had excess stress and smoking than unaffected relatives only in families with a negative family history of duodenal ulcer. In the subjects of present study, especially in those with a positive family history behavioral factors had a minor influence on development of duodenal ulcer in a familial basis.

In conclusion, genetic factors such as hyperpepsinogenemia 1 and non secretor status play an important role on the susceptibility of duodenal ulcer and hypergastrinemia may serve as subclinical marker for familial aggregation of duodenal ulcer, but not ulcer susceptibility.

\section{REFERENCES}

1) Doll $R$ and Buch $J$ : Hereditory factors in peptic ulcer. 15: 135, 1950.

2) Gotlieb-Jensen K: Peptic ulcer: genetic and epidemiological aspects based on twin studies. Copenhagen, Munksgaard, 1972.

3) Aird I, Bental HH, Mehigaro JA, et al: The blood groups in relation to peptic ulceration and carcinoma of the colon, rectum, breast and bronchus. Br Med J 2: $315,1954$.

4) Clarke CA, Edwards JW, Haddock DRW, et al: ABO blood groups and secretor character in duodenal ulcer. Br Med J 2: 725, 1956.

5) Rotter JI, Peterson G, Samloff IM, et al: Genetic heterogeneity of hyperpepsinogenemic 1 and normopepsinogenemic 1 duodenal ulcer disease. Ann Int Med 91: 372, 1979.

6) Sumii $K$, Uemura $N$, Inbe $A$, et al: Familial aggregation of duodenal ulcer and an autosomal dominant inheritance of hyperpepsinogenemia 1 . Hiroshima J Med Sci 35: 171, 1986.

7) Waft L, Roberts NB, and Taylor WH: Hereditory aspects of duodenal ulceration: pepsin 1 secretion in relation to $\mathrm{ABO}$ blood groups and $\mathrm{ABH}$ secretor status. J Med Genetics 16: 423, 1980.

8) Sumii K, Yokoyama Y, Matsui Y, et al: The increased antral gastrin content and its release in response to test meal in patients with duodenal ulcer. Hiroshima J Med Sci 28: 221, 1979.

9) Lam SK, and Ong GB: Relationship of postprandial serum gastrin response to sex, body weight, blood group status, familial dyspepsia, duration, and age of onset of ulcer symptoms in duodenal ulcer. Gut 21: 528, 1980. 